\title{
Mortality by COVID-19 in adults with acute myeloid leukemia: a survey with hematologists in Brazil
}

\author{
Evandro M. Fagundes ${ }^{1}$ - Naira N. Neto ${ }^{1}$ - Lorena M. Caldas ${ }^{2}$. Jordana R. Aragão ${ }^{3}$ - Ana Beatriz F. Gloria ${ }^{4,5}$. \\ Leonardo G. Leite ${ }^{6,7} \cdot$ Paula Bastos $^{8} \cdot$ Carolina M. Fernandes $^{9} \cdot$ Mariana Chalup $^{5} \cdot$ Rosa Arcuri $^{10} \cdot$ Olivia G. Fagundes $^{11}$
}

Received: 13 June 2021 / Accepted: 29 August 2021 / Published online: 17 September 2021

(c) The Author(s), under exclusive licence to Springer-Verlag GmbH Germany, part of Springer Nature 2021

\section{Dear Editor,}

COVID-19 caused by the novel coronavirus SARS-COV-2 and first detected in Wuhan, China in 2019, has become one of the worst pandemics in history [1,2]. Although approximately $50 \%$ of the infected individuals are asymptomatic, some may develop severe cytokine release syndrome with intense immune response and endothelial damage [3]. Obesity, hypertension, diabetes, COPD, advanced age, and malignancy have been listed as risk factors for severe disease, hospitalization, admission in intensive care unit, and death $[4,5]$. Patients with hematological malignancies also have a higher risk of severe events and among all of them, acute myeloid leukemia (AML) seems to have the highest risk for death by COVID-19 [6].

Evandro M. Fagundes

evandro.fagundes@medicos.oncoclinicas.com

1 Oncoclínicas Belo Horizonte, Rua dos Otoni 881, 15o andar, Belo Horizonte, Minas Gerais 30150-270, Brazil

2 Centro de Oncologia Dr, Oswaldo Leite, Aracaju, Brazil

3 Instituto Nacional Do Câncer, Rio de Janeiro, Brazil

4 Hospital das Clínicas, Universidade Federal de Minas Gerais, Belo Horizonte, Brazil

5 Hospital Luxemburgo, Belo Horizonte, Brazil

6 Hospital Central Do Exército, Rio de Janeiro, Brazil

7 Oncoclínicas Rio de Janeiro, Rio de Janeiro, Brazil

8 Santa Casa de Misericórdia de Belo Horizonte, Belo Horizonte, Brazil

9 Hospital Nossa Senhora das Neves-João Pessoa, João Pessoa, Brazil

10 Oncoclínicas, Recife, Brazil

11 Faculdade de Medicina, Ciências Médicas de Minas Gerais, Belo Horizonte, Brazil
Because avoiding medical services visits or prolonged stays in hospital is not an option for AML patients, these individuals have a higher chance of getting in contact and being infected by SARS-COV-2. Once infected, these patients may be at high risk for severe complications and death as they have immunosuppression, neutropenia, and epithelial mucosal barrier damage [7]. AML affects individuals of all ages whom may be in different hematological scenarios such as in remission or with active disease that may be treated with intensive chemotherapy or low intensity treatment. The impact of COVID-19 in those different AML scenarios is unknown. Our aim is to report a survey conducted with Brazilian hematologists who attended AML patients with COVID-19, to evaluate the mortality rate seen by those doctors among their patients and any potential risk factor for death.

\section{Methods}

From May 5 to May 19, 2021, we conducted a survey with 178 hematologists within different regions of Brazil. We asked about adult patients ( $>18$ years) with AML who had the COVID-19 diagnosis confirmed by RT-PCR. We collected data about age, gender, possible source of contamination by SARS-COV-2 (hospital vs community), previous vaccination, moment of the AML treatment (pre-treatment, during induction, post remission, off treatment), the status of AML when COVID was diagnosed (remission vs active disease) and the outcomes related to COVID-19 (death, delay of treatment, relapse of AML). We considered the answers provided by the doctors as events that are reported as counts and percentages. We use Mann-Whitney $U$, Fisher's exact, or chi-square tests when appropriate. The $p$ value $<0.05$ considered significant. Statistics were performed using the Social Science Statistics at https://www.socscistatistics.com. 


\section{Results and discussion}

We received answers from 10 doctors representing 10 cancer centers. Four medical centers involved in this survey were exclusively part of the Brazilian Public Health System and 5 exclusively part of the private system. One center was part of both public and private systems. Seven were general hospitals, while 3 were exclusive for cancer treatment. Only one hospital has high-efficiency particulate air (HEPA) filtration for leukemia patients. The patients were treated in private isolate rooms in five hospitals. According to the protective measures to diminish SARS-COV-2 transmission, we found that only one center regularly screens health personnel, only two tested patients prior to hospital admission and all of them allowed companions with patients, although only one center screens them for COVID-19 pre-admission. The doctors surveyed provided data on 33 patients ( 22 females), that were admitted mainly through urgent and emergency care unit. The median age at the COVID-19 diagnosis was 60 years (19 to 79 years). Only one had been previously vaccinated. The place of contamination with SARSCOV-2 could not be identified in two cases, while in 21 cases $(63 \%)$ in-hospital transmission was presumed to be the source of infection. In 20 patients (60.6\%), COVID-19 was diagnosed when the patient had active AML, while in 13 patients, (39.3\%) AML was in remission. The diagnosis was done in the context of symptomatic patients except for one whose diagnosis was done in the context of investigation for febrile neutropenia. Twelve patients had COVID-19 diagnosis before starting AML treatment, 6 during intensive chemo induction remission, 3 during intensive chemo consolidation, 9 while in low-intensity therapy and 2 during treatment of relapse. Only one patient had completed AML treatment and was in remission. There were 18 deaths attributed to COVID-19 (54.5\%), of which 15 (83\%) had active AML and $3(17 \%)$ were in AML remission $(p=0.0052)$. We did not identify any other factor that could be associated to death. Among the 15 patients who survived COVID-19, 8 (53\%) had some delay in their AML treatment.

Despite its limitations, this exploratory report addressing specifically AML and COVID-19. It brings up some points to consider: First, most patients were presumed to be infected in hospital, which reinforces the need for taking measures to control the dissemination of COVID-19 inside the hospital environment. This is particularly relevant since the seroconversion rate after COVID-19 can be lower in AML patients than that expected for the general population. Besides, the viral shedding may be prolonged in immunocompromised persons which may facilitate dissemination in hospital if protective precautions are not taken [8]. In this survey only one patient had been vaccinated before the diagnosis of COVID-19. This patient was in AML remission and did not die. The question of whether previous SARS-COV-2 vaccine could diminish the mortality rate in our population cannot be answered. In fact, this may be an intriguing point since patients with hematologic malignancies, particularly those with B-cell lymphoid neoplasm and multiple myeloma, may not have a good immune response [9]. Second, published recommendations on management of patients with hematological malignancies and COVID-19 were based more in common sense rather than on scientific evidence $[7,10,11]$. Our work adds to this, suggesting that patients with active AML possibly have more risk of death from COVID-19 and that patients on AML treatment did not have better outcomes. Together, these findings lead us to speculate that the best strategy could be postponing the beginning of AML treatment as long as it is safe, as others have also suggested [11]. This suggestion is supported by retrospective studies indicating that the time from diagnosis to treatment may not affect the final outcome for AML patients [12]. Of note, 5 of 12 patients who had COVID19 diagnosis before beginning AML treatment were alive and COVID free by the time the survey was made. Patients in remission who needs post remission therapy should be screened for SARS-COV-2 before starting chemotherapy and in case of positivity consideration should be given to postponing it for two or more weeks [11]. Third, although the role of SARS-COV-2 cannot be ascertained, our survey seems to confirm the high risk of death due to COVID-19 in patients with AML. Fourth, more than $50 \%$ of patients who survived COVID-19 had a delay in their treatment; the impact of this delay on AML survival remains uncertain and should be evaluated in future studies.

In conclusion, AML patients seem to have a very high risk of death when infected by SARS-COV-2. Furthermore, even when recovered from COVID-19, those patients may suffer a delay in their treatment. Further reports are needed to formulate evidence-based recommendations.

Supplementary Information The online version contains supplementary material available at https://doi.org/10.1007/s00277-021-04659-w.

Data availability The original data is available from the correspondent author.

\section{Declarations}

Ethics approval All authors collected and provided data in accordance with ethical standards and with the Helsinki Declaration of 1975, as revised in 2008. As it is a retrospective survey ethical committee approval and formal informed consent were not required.

Competing interests The authors declare no competing interests. 


\section{References}

1. Huang C, Wang Y, Li X, Ren L, Zhao J, Hu Y, Zhang L, Fan G, Xu J, Gu X, Cheng Z, Yu T, Xia J, Wei Y, Wu W, Xie X, Yin W, Li H, Liu M, Xiao Y, Gao H, Guo L, Xie J, Wang G, Jiang R, Gao Z, Jin Q, Wang J, Cao B (2020) Clinical features of patients infected with 2019 novel coronavirus in Wuhan China. The Lancet 395(10223):497-506. https://doi.org/10.1016/S0140-6736(20) 30183-5

2. WHO Coronavirus (COVID-19) (2021) Dashboard. WHO. https:// covid19.who.int/. Accessed 19 May 2021

3. Guan WJ, Ni ZY, Hu Y et al (2020) Clinical Characteristics of Coronavirus Disease 2019 in China. N Engl J Med 382:17081720. https://doi.org/10.1056/NEJMoa2002032

4. Guan WJ, Liang WH, Zhao YGuan WJ, Liang WH, Zhao Y et al (2020) Comorbidity and its impact in 1590 patients with COVID-19 in China: a Nationwide analysis. Eur Respir J 14;55(5):2000547. https://doi.org/10.1183/13993003.00547-2020

5. Liang W, Guan W, Liang Chen R, W, Guan W, Chen R, et al (2020) Cancer patients in SARS-CoV-2 infection: a nationwide analysis in China. Lancet Oncol 21(3):335-337. https://doi.org/ 10.1016/S1470-2045(20)30096-6

6. Passamonti F, Cattaneo C, Arcaini L et al (2020). Clinical characteristics and risk factors associated with COVID-19 severity in patients with haematological malignancies in Italy: a retrospective, multicenter, cohort study. Lancet Haematol Lancet Oncol7(10):e737e745. https://doi.org/10.1016/S2352-3026(20)30251-9

7. Paul S, Rausch CR, Jain N, Kadia T, Ravandi F, DiNardo CD, Welch MA, Dabaja BS, Daver N, Garcia-Manero G, Wierda W, Pemmaraju N, Bravo GM, Thompson P, Verstovsek S, Konopleva M, Kantarjian H, Jabbour E (2021) Treating Leukemia in the Time of COVID-19. Acta Haematologica 144(2):132-145. https://doi. org/10.1159/000508199

8. Passamonti F, Romano A, Salvini M, Merli F, Della Porta MG, Bruna R, Coviello E, Romano I, Cairoli R, Lemoli R, Farina F, Venditti A, Busca A, Ladetto M, Massaia M, Pinto A, Arcaini L, Tafuri A, Marchesi F, Fracchiolla N, Bocchia M, Armiento D, Candoni A, Krampera M, Luppi M, Cardinali V, Galimberti S, Cattaneo C, La Barbera EO, Mina R, Lanza F, Visani G, Musto P, Petrucci L, Zaja F, Grossi PA, Bertù L, Pagano L, Corradini P, Derenzini E Marchetti M, Scattolin AN, Corso A, Tosi P, Gherlinzoni F, Passerini CG, Cavo M, Fava C, Turrini M, Visco C, Zappasodi P, Merli M, Mora B, Vannucchi AM (2020) COVID-19 elicits an impaired antibody response against SARS-CoV-2 in patients withhaematological malignancies. British Journal of Haematology. https://doi.org/10.1111/bjh.17704
9. Agha ME, Blake M, Chilleo C, Wells A, Haidar G (2021) Suboptimal Response to Coronavirus Disease 2019 Messenger RNA Vaccines in Patients With Hematologic Malignancies: A Need for Vigilance in the Postmasking Era. Open Forum Infectious Diseases 8(7). https://doi.org/10.1093/ofid/ofab353

10. Brissot E, Labopin M, Baron F, Bazarbachi A, Bug G, Ciceri F, Esteve J, Giebel S, Gilleece MH, Gorin N-C, Lanza F, Peric Z, Ruggeri A, Sanz J, Savani BN, Schmid C, Shouval R, Spyridonidis A, Versluis J, Nagler A, Mohty M (2021) Management of patients with acute leukemia during the COVID-19 outbreak: practical guidelines from the acute leukemia working party of the European Society for Blood and Marrow Transplantation. Bone Marrow Transplantation 56(3):532-535. https://doi.org/10.1038/ s41409-020-0970-x

11. Zeidan AM, Boddu PC, Patnaik MM, Bewersdorf JP, Stahl M, Rampal RK, Shallis R, Steensma DP, Savona MR, Sekeres MA, Roboz GJ, DeAngelo DJ, Schuh AC, Padron E, Zeidner JF, Walter RB, Onida F, Fathi A, DeZern A, Hobbs G, Stein EM, Vyas P, Wei AH, Bowen DT, Montesinos P, Griffiths EA, Verma AK, Keyzner A, Bar-Natan M, Navada SC, Kremyanskaya M, Goldberg AD, Al-Kali A, Heaney ML, Nazha A, Salman H, Luger S, Pratz KW, Konig H, Komrokji R, Deininger M, Cirici BX, Bhatt VR, Silverman LR, Erba HP, Fenaux P, Platzbecker U, Santini V, Wang ES, Tallman MS, Stone RM, Mascarenhas J (2020) Special considerations in the management of adult patients with acute leukaemias and myeloid neoplasms in the COVID-19 era: recommendations from a panel of international experts. Lancet Haematol 7(8):e601-e612 . https://doi.org/10.1016/S2352-3026(20) 30205-2

12. Röllig C, Kramer M, Schliemann C, Mikesch J-H, Steffen B, Krämer A, Noppeney R, Schäfer-Eckart K, Krause SW, Hänel M, Herbst R, Kunzmann V, Einsele H, Jost E, Brümmendorf TH, Scholl S, Hochhaus A, Neubauer A, Sohlbach K, Fransecky L, Kaufmann M, Niemann D, Schaich M, Frickhofen N, Kiani A, Heits F, Krümpelmann U, Kaiser U, Kullmer J, Wass M, Stölzel F, von Bonin M, Middeke JM, Thiede C, Schetelig J, Berdel WE, Ehninger G, Baldus CD, Müller-Tidow C, Platzbecker U, Serve H, Bornhäuser M (2020) Does time from diagnosis to treatment affect the prognosis of patients with newly diagnosed acute myeloid leukemia? Blood 136(7):823-830. https://doi.org/10.1182/ blood.2019004583

Publisher's note Springer Nature remains neutral with regard to jurisdictional claims in published maps and institutional affiliations. 